I BIENAL LATINOAMERICANA DIDH

\title{
Comunidad de práctica en derechos humanos y constitucionalismo transformador en América Latina
}

\author{
Communities of practice in human rights and transformative \\ constitutionalism in Latin America
}

\begin{abstract}
Armin von Bogdandy
Instituto Max Planck de Derecho Público Comparado y Derecho Internacional, Alemania
\end{abstract}

René Urueña

Universidad de los Andes, Colombia

\begin{abstract}
RESUMEN En los últimos años, se ha venido desarrollando en América Latina una especie de derecho común de los derechos humanos, lo que entendemos como ius constitutionale commune. En el centro del surgimiento de este régimen se encuentran la Comisión Interamericana (CIDH) y la Corte Interamericana de Derechos Humanos (Corte IDH). En este capítulo exploramos cómo y por qué funciona el constitucionalismo transformador en América Latina, que es promovido por un grupo de personas que buscan enfrentar la violencia, la exclusión social y la debilidad institucional a través del derecho. Sostenemos que la Corte Interamericana ha desarrollado dos aspectos que han contribuido a su consolidación en un difícil contexto. Por un lado, jurídicamente la Corte ha mantenido una interpretación evolutiva de los tratados, junto con doctrinas de control de convencionalidad y el bloque de constitucionalidad, lo que ha generado estándares jurídicos regionales. Por otra parte, ha desarrollado una práctica social, en la que interactúa con distintos actores nacionales, regionales e internacionales para avanzar la agenda de los derechos humanos.
\end{abstract}

PALABRAS CLAVE Corte IDH, derechos humanos, ius constitutionale commune, práctica social, bloque de constitucionalidad, comunidad de práctica en derechos humanos.

ABSTRACT In recent years, a kind of common human rights law has developed in Latin America, what we understand as ius constitutionale commune. At the center of the emergence of this regime are the Inter-American Commission (IACHR) and the Inter-American Court of Human Rights (Inter-American Court). In this chapter we 
explore how and why transformative constitutionalism works in Latin America, which is promoted by a group of people who seek to confront violence, social exclusion, and institutional weakness through the law. We maintain that the Inter-American Court has developed two aspects that have contributed to its consolidation, in a difficult context. On the one hand, the Court has legally maintained an evolutionary interpretation of the treaties, together with doctrines of control of conventionality and the constitutionality block, generating regional legal standards. On the other hand, it has developed a social practice, in which it interacts with different national, regional and international actors to advance the human rights agenda.

KEYWORDS Interamerican Court of Human Rights, human rights, ius constitutionale commune, social practice, block of constitutionality, community of practice in human rights.

\section{Introducción}

El 18 de julio de 1978, la Convención Americana de Derechos Humanos entró en vigor. Cuarenta años después, se ha convertido en la piedra angular del constitucionalismo transformador en América Latina; esto es, una interpretación y aplicación de las normas constitucionales inspirada en la intención de alcanzar cambios sociales profundos. ${ }^{1}$ Por supuesto, el constitucionalismo transformador no está restringido a América Latina (Hailbronner, 2017). La Corte Suprema india (Sripati, 2007: 92-103) y la Corte Suprema sudafricana (Roux, 2009) ${ }^{2}$ también han desarrollado una jurisprudencia distintiva para abordar problemas estructurales, en particular profundos patrones de injustica. ${ }^{3}$ Sin embargo, dos características latinoamericanas resaltan en este contexto global, las que hacen del constitucionalismo transformador un fenómeno diferente en esa región. Primero, el constitucionalismo transformador latinoamericano no es solo un proceso interno, sino que está respaldado por un régimen internacional, que presenta dos instituciones operativas: la Comisión Interamericana (CIDH) y la Corte Interamericana de Derechos Humanos (Corte IDH) (Acosta Alvarado: 2015). En segundo lugar, este sistema de dos niveles se complementa con una interacción horizontal entre las instituciones nacionales que comparten esta perspectiva transformadora: jueces nacionales, así como fiscales, defensores del pueblo, administraciones especializadas y, lo que es más importante, organizaciones no gubernamentales (ONG) (Azuero Quijano: 2009).

1. El término original proviene de Klare (1998: 150).

2. Para Venter (2018: 165), por el contrario, la noción de transformación en Sudáfrica se ha vuelto «flexible y comprometida ideológicamente».

3. Para el fenómeno global, véase Bonilla (2013). 
Como parte de esta amplia red de interacciones transnacionales, la Corte Interamericana ha desarrollado una jurisprudencia que aborda algunos de los problemas estructurales centrales de la región, y ha fallado sobre asuntos altamente controversiales. Al decidir temas como la impunidad por violaciones graves de los derechos humanos en Perú y Uruguay, ${ }^{4}$ la inclusión de los pueblos indígenas en el proceso político en Ecuador, ${ }^{5}$ la protección de los derechos LGBTI en Chile ${ }^{6}$ y la complicidad del Estado colombiano con la violencia paramilitar, ${ }^{7}$ la Corte ha alimentado una especie de derecho común de los derechos humanos, un ius constitutionale commune en América Latina, que ha transformado la realidad en la región (von Bogdandy y otros: 2017). ${ }^{8}$

Este capítulo explora cómo y por qué el constitucionalismo transformador internacional funciona en América Latina. Para hacerlo, se enfoca en la práctica de la Corte Interamericana de Derechos Humanos, de modo de ofrecer una lectura contextualizada de sus decisiones y procedimientos como una parte pequeña, pero vibrante y esencial, de la comunidad latinoamericana de derechos humanos, un grupo determinado y especializado de personas que confronta, por medio del derecho, a la violencia, la exclusión social y la debilidad institucional.

Con este objetivo, el capítulo describe los instrumentos y técnicas que la Corte Interamericana ha utilizado para actuar en este difícil contexto, ayudando a establecer una práctica transformadora en la región. En particular, se centra en dos dimensiones claves de dicha práctica: la dimensión jurídica y la dimensión social. Jurídicamente, la interpretación evolutiva de los tratados por parte de la Corte Interamericana, junto con las doctrinas del control de convencionalidad y el bloque de constitucionalidad, han creado una metodología dinámica para establecer estándares jurídicos que aborden los desafíos importantes que surgen en la región. Esta dimensión es analizada en la segunda parte.

4. Caso Barrios Altos con Perú, Corte Interamericana de Derechos Humanos, serie C núm. 75, fondo, 14 de marzo de 2001; caso Barrios Altos con Perú, serie C núm. 83, interpretación de la sentencia en cuanto al fondo, 3 de septiembre de 2001; caso La Cantuta con Perú, serie C núm. 162, fondo, reparaciones y costas, 29 de noviembre de 2006; caso Gelman con Uruguay, serie C núm. 221, fondo y reparaciones, 24 de febrero de 2011.

5. Caso Pueblo Indígena Kichwa de Sarayaku con Ecuador, Corte Interamericana de Derechos Humanos, serie C núm. 245, fondo y reparaciones, 27 de junio de 2012.

6. Caso Atala Riffo e Hijas con Chile, Corte Interamericana de Derechos Humanos, serie C núm. 239, fondo, reparaciones y costas, 24 de febrero de 2012.

7. Sentencia del caso Masacre de Mapiripán con Colombia, Corte Interamericana de Derechos Humanos, serie C núm. 134, 15 de septiembre de 2005, párr. 123; sentencia del caso Masacre de la Rochela con Colombia, fondo, reparaciones y costas, serie C núm. 163, 11 de mayo de 2007, párrs. 82, 93 y 101.a.

8. Para terminología similar, véase Restrepo Piedrahita (1978: 137) y Häberle y Kotzur (2003). 
A su vez, la tercera parte describe la práctica social. Proponemos que las operaciones jurídicas son solo un aspecto de un campo social mucho más amplio: los miembros de la comunidad latinoamericana de derechos humanos, que están presentes en todo el continente y que conforman una comunidad de práctica.

La cuarta parte concluye con algunas reflexiones sobre el cuadragésimo aniversario de la Corte Interamericana de Derechos Humanos.

\section{Algunas innovaciones jurídicas}

Empecemos con la dimensión jurídica. En particular, las nociones de constituciones abiertas, bloque de constitucionalidad, la interpretación evolutiva y el control de convencionalidad. Para entender estos conceptos, debemos retroceder en el tiempo.

En 1960, cuando la Convención Americana fue discutida, la mayoría de los países latinoamericanos estaban bajo Gobiernos autoritarios o represivos. Los años setenta fueron un periodo particularmente oscuro. No fue hasta 1980 cuando los países de la región comenzaron la lenta transición hacia la democracia, buscando asegurar que «Nunca más»» las violaciones a derechos humanos tendrían cabida en sus sociedades. Para lograrlo, llegaron a un consenso social a través de la aprobación de nuevos textos constitucionales: Brasil en 1988, Colombia en 1991, Paraguay en 1992, Perú en 1993, Ecuador en 1998 y 2008, Venezuela en 1999 y Bolivia en 2009 (Morales Antoniazzi, 2014). Otros países introdujeron reformas sustanciales: por ejemplo, Argentina en 1994 y México en 2011. El faltante es Chile, donde la constitución promulgada bajo el régimen de Pinochet en 1980 continúa vigente - con algunas reformas importantes- $y$ donde, sin embargo, el proceso de reforma constitucional parece prometer una transformación constitucional de importancia (Atria, Salgado y Wilenmann, 2020).

La mayoría de las constituciones de la región introdujeron una amplia sección de derechos fundamentales, incluyendo derechos económicos y sociales (Rodríguez Garavito, 2015). También incluyeron cláusulas que intentaban mejorar la participación democrática, ya sea por participación directa o a través de una mejor representación. ${ }^{10}$ Todo lo anterior significó un cambio profundo: de ver el derecho como el producto de una élite dedicada a obstruir el cambio social — una visión sostenida por progresistas de la región entre 1960 y 1970 (Novoa Monreal, 1975)—, a verlo como un instrumento crucial para la transformación social. En una región dominada en

9. Véase Comisión Nacional sobre la Desaparición de Personas (1984).

10. Para Venezuela, Ceballos Méndez (2009: 43-90) y Salamanca (200o). Para Chile, Colombia y Guatemala, Huerta Malbrán (200o). Para Perú, Cuesta López, López Aguilar y Rodríguez-Drincourt Álvarez (2008) y Márquez Restrepo, Pastrana Buelvas y Hoyos Vásquez (2009). Para Ecuador y Argentina, Welp (2008). 
ese momento por el formalismo jurídico, las fuerzas detrás de estos cambios constitucionales buscaban proteger los derechos en la vida real y garantizar una verdadera participación en la toma de decisiones en los procesos democráticos emergentes (Uprimny, 2010). ${ }^{11}$

Como complemento a este proceso, las nuevas constituciones «abrieron» el derecho nacional al derecho internacional, en particular hacia el derecho de los derechos humanos, a través de cláusulas que incorporaban el derecho internacional al derecho nacional. De esta forma, las constituciones nacionales superaron la comprensión rígida de soberanía (Morales Antoniazzi y Saavedra Alessandri, 2017). Aun cuando hay variaciones significativas entre estas cláusulas, con Chile siendo la «menos abierta», el resultado general fue una integración profunda del derecho nacional y el derecho internacional de los derechos humanos, en el cual la Convención Americana y sus instituciones juegan un papel clave en el derecho constitucional nacional. ${ }^{12}$ Desde el punto de vista doctrinal, esto es concebido en la mayoría de los países como un «bloque de constitucionalidad», el cual está compuesto por la constitución nacional y la Convención (Góngora Mera, 2011), razón por la cual la Convención puede ser considerada como parte del derecho nacional en muchos Estados de la región (Binder, 2010: 156-188).

A pesar de haber sido estudiada de manera separada, las garantías sustantivas de los derechos constitucionales, de una parte, y la «apertura» constitucional, de otra, son de hecho dos procesos complementarios. En el tiempo de regímenes dictatoriales, la sociedad civil latinoamericana contaba en gran medida con las instituciones internacionales y extranjeras para avanzar en los cambios, como lo observaron Sikkink y Keck (1998) al final de los noventa en Argentina, Chile y México. La apertura al derecho internacional puede ser leída como una cristalización constitucional formal de esta estrategia: un medio para formalizar el espacio que activistas habían logrado en su lucha contra regímenes autoritarios.

En sincronía con estos cambios, los jueces y abogados de la Corte Interamericana, con un alto compromiso por los derechos humanos, desarrollaron dos teorías doctrinales que soportan estos desarrollos constitucionales. La primera fue la interpretación evolutiva de los tratados de derechos humanos. Fue allí cuando la Corte empezó a adaptar el significado de las garantías enmarcadas en la Convención, en su mayoría tomadas de la Convención Europea de Derechos Humanos, teniendo en consideración los retos específicos de América Latina. Para el tribunal interamerica-

11. Véase Dezalay y Garth (2002). En Colombia, Rodríguez Garavito (2009).

12. Véase Cumplido Cereceda (1996). Sobre Bolivia, véanse los artículos 257 y 410 de la Constitución Plurinacional de Bolivia, y Villarroel Alarcón (2017: 29-66). Sobre Ecuador, véase el artículo 424 de la Constitución de la República de Ecuador, y Caicedo Tapia (2009). Sobre Brasil, véase el artículo 5 de la Constitución y la Enmienda Constitucional 45. Este resumen está basado en Urueña (2019). 
no, «los tratados de derechos humanos son instrumentos vivos, los cuales deben ser interpretados en consonancia con la evolución de los tiempos y las actuales condiciones de vida». ${ }^{13}$ A través de la interpretación evolutiva, la Corte expandió y profundizó la protección de diferentes derechos con un enfoque latinoamericano, como se puede ver en la jurisprudencia - ahora reconocida a nivel mundial - sobre desaparición forzada, ${ }^{14}$ privacidad, ${ }^{15}$ libertad personal, ${ }^{16}$ derechos de los niños, ${ }^{17}$ propiedad colectiva, ${ }^{18}$ igualdad y no discriminación. ${ }^{19}$

El segundo desarrollo doctrinal es el «control de convencionalidad», ${ }^{20}$ que aplica la interpretación evolutiva directamente en la vida de la gente. En este sentido, la doctrina llama a las cortes nacionales a hacer revisiones judiciales de cualquier acto nacional, incluyendo leyes nacionales, sobre la base de la Convención Americana, y tomando en consideración la interpretación de la Corte Interamericana. ${ }^{21} \mathrm{El}$ control de convencionalidad transforma cada juez nacional en un juez interamericano, que respeta «el marco de sus respectivas jurisdicciones y sus correspondientes reglas procedimentales». ${ }^{22}$ La Corte Europea de Derechos Humanos nunca se ha atrevido a

13. Corte IDH, Opinión Consultiva OC-16/99, 1 de octubre de 1999, solicitada por los Estados Unidos Mexicanos sobre «El derecho a la información sobre la asistencia consular en el marco de las garantías del debido proceso legal», serie A núm. 16, párr. 114.

14. Sentencia del caso Velásquez Rodríguez con Honduras, Corte Interamericana de Derechos Humanos, 29 de julio de 1988, párr. 155; sentencia del caso Godínez Cruz con Honduras, fondo, 20 de enero de 1989, párr. 155 .

15. Caso Artavia Murillo y otros (Fertilización In Vitro) con Costa Rica, Corte Interamericana de Derechos Humanos, excepciones preliminares, fondo, reparaciones y costas, serie C núm. 257, 28 noviembre de 2012, párr. 272.

16. Caso Masacres de Ituango con Colombia, Corte Interamericana de Derechos Humanos, serie C núm. 148, 1 de julio de 2006, párrs. 154-158.

17. Caso Niños de la Calle (Villagrán Morales y otros) con Guatemala, Corte Interamericana de Derechos Humanos, fondo, serie C núm. 63, 19 de noviembre de 1999, párrs. 191-198; caso Hermanos Gómez Paquiyauri con Perú, fondo, reparaciones y costas, serie C núm. 110, 8 de julio de 2004, párrs. 164-167.

18. Caso Comunidad Mayagna (Sumo) Awas Tingni con Nicaragua, Corte Interamericana de Derechos Humanos, fondo, reparaciones y costas, serie C núm. 79, 31 de agosto de 2001, párr. 148.

19. Caso Atala Riffo y Niñas con Chile, Corte Interamericana de Derechos Humanos, fondo, reparaciones y costas, serie C núm. 239, 24 de febrero de 2012, párrs. 83 y 91.

20. Caso Almonacid Arellano y Otros con Chile, Corte Interamericana de Derechos Humanos, objeciones preliminares, fondo, reparaciones y costas, serie C núm. 154, 26 de septiembre de 2006. Sobre la doctrina, véase generalmente Ferrer Mac-Gregor (2015) y Henríquez y Morales Antoniazzi (2017).

21. Caso Tibi con Ecuador, Corte Interamericana de Derechos Humanos, objeciones preliminares, fondo, reparaciones y costas, serie C núm. 114, 7 de septiembre de 2004, párr. 3 voto concurrente del juez García-Ramírez.

22. Véase la sentencia del caso Aguado Alfaro y otros Perú, Corte Interamericana de Derechos Humanos, objeciones preliminares, fondo, reparaciones y costas, 24 de noviembre de 2006, párr. 128; y la sentencia del caso Gelman con Uruguay, fondo y reparaciones, 24 de febrero de 2011, párr. 193. 
ir tan lejos (Burgorgue-Larsen, 2017), por lo que el Tribunal Interamericano se parece más a la Corte Europea de Justicia y su tesis de los efectos de sus decisiones. ${ }^{23}$

La Corte Interamericana también tiene jurisdicción para revisar la conformidad de leyes nacionales con la Convención (Sagüés, 2010: 120; Nash Rojas, 2013: 491-492). En casos excepcionales, se han declarado normas nacionales «sin efectos jurídicos»" por violar la Convención. Estos actos amplían en gran medida el alcance de ese instrumento y crean un verdadero sistema de aplicación descentralizado, compuesto no solo por órganos interamericanos, sino potencialmente por miles de autoridades nacionales. $^{25}$

La apertura constitucional, la interpretación evolutiva y el control de constitucionalidad proveen una estructura jurídica que hace posible al constitucionalismo internacional trasformador, mediante la introducción de un conjunto de normas y principios que pueden ser consideradas un verdadero derecho común de derechos humanos en América Latina (von Bogdandy, 2020; von Bogdandy, Fix-Fierro y Morales Antoniazzi, 2014: 156-199; von Bogdandy y Morales Antoniazzi, 2020): un derecho común que es desarrollado por muchos actores de la comunidad latinoamericana de derechos humanos, transformándolo en un campo jurídico y en una práctica social en la región. Este derecho común define y es definido por los operadores jurídicos de la región. Por una parte, el derecho común encuadra jurídicamente la práctica de la Corte Interamericana, al definir los poderes de la Corte, así como sus estándares

23. Caso seminal 26/62, Van Gend en Loos [1963] ECR 1, 11 y ss. Sobre la expansión de la jurisdicción de la Corte de Justicia, véase Stein (1981).

24. Véase el caso La Cantuta con Perú, Corte Interamericana de Derechos Humanos, fondo, reparaciones y costas, serie C núm. 162, 29 de noviembre de 2006, párr. 189, juez Sergio García Ramírez, párrs. 4-5; y caso Barrios Altos con Perú, Corte Interamericana de Derechos Humanos, fondo, serie C núm. 75, 14 de marzo de 2001.

25. El alcance de las autoridades nacionales a cargo de realizar el control de convencionalidad se ha refinado en la jurisprudencia. En Cabrera García con México, la Corte sostuvo que todos los órganos estatales, no solo las autoridades judiciales, están obligados a realizar dicha revisión (sentencia del 26 de noviembre de 2010, excepción preliminar, fondo y ostas, párr. 225). Sin embargo, esta interpretación corría el riesgo de una aplicación descoordinada de los estándares interamericanos a nivel interno. Por lo tanto, la Corte buscó limitar el alcance de la doctrina al aclarar que el control de convencionalidad debe ser ejercido, de oficio, por las autoridades estatales, «evidentemente en el marco de su respectiva jurisdicción y las normas procesales correspondientes». Véase la sentencia del caso Empleados Cesados del Congreso (Aguado-Alfaro y otros) con Perú, objeciones preliminares, fondo, reparaciones y costas, 24 de noviembre de 2006, párr. 128; sentencia del caso Gelman con Uruguay, fondo y reparaciones, 24 de febrero de 2011, párr. 193. En este contexto, el control de convencionalidad implica que las instituciones nacionales tienen el deber de aplicar el derecho internacional, siempre que sea compatible con las normas internas de jurisdicción y procedimiento, doctrina mucho menos radical de lo que parecería inicialmente. La discusión de esta dimensión del control de convencionalidad se basa en Urueña, supra nota 24 . 
sustantivos. Al mismo tiempo, el derecho común de los derechos humanos ha influenciado las prácticas de la Corte, sus decisiones y su voluntad de presionar por una efectiva protección de los derechos humanos.

\section{El derecho común de los derechos humanos como práctica social}

En América Latina, el concepto de derecho común de los derechos humanos describe un campo jurídico en el sentido bourdieusiano, lo que se traduce en una práctica social. Un campo es un espacio donde

las fuerzas se imponen a los agentes que participan en él, y un escenario de luchas dentro del cual los agentes se enfrentan entre sí, con medios y fines diferenciados de acuerdo con su posición en la estructura del campo de fuerzas, contribuyendo así a conservar o transformar su estructura (Reed-Danahay, 2005: 32). ${ }^{26}$

Como uno de esos campos, el derecho interamericano de los derechos humanos se ha convertido en un fenómeno de la vida real. En primer lugar, es una práctica social: un grupo de personas que interactúan, sobre la base de la Convención, para impulsar sus agendas y cumplir lo que ven como sus mandatos. Esta comunidad de expertos está compuesta por diferentes actores: ONG transnacionales que presentan casos ante el sistema interamericano, organizaciones de base que utilizan estos derechos para proteger a las víctimas en sus territorios, clínicas en facultades de Derecho que presentan informes amicus curiae, tribunales nacionales que interpretan y aplican Convención y jurisprudencia de la Corte IDH, funcionarios que trabajan en derechos humanos para Gobiernos nacionales, académicos que escriben y enseñan derecho de los derechos humanos, los comisionados y jueces del sistema interamericano, y también políticos con una agenda de derechos humanos.

La noción de comunidad de práctica surge en 1991, cuando el antropólogo Jean Lave y el científico informático Etienne Wenger cristalizaron la noción de aprendizaje situado, la idea de que el aprendizaje es en lo fundamental un proceso social. Por lo tanto, el aprendizaje no solo está conectado a conceptos abstractos, sino también a la acción, lo que implica la socialización (Lave y Wenger, 1991). Wenger defendió la idea reformulándola como una forma organizativa: grupos de personas, unidas de manera informal por experiencias compartidas y pasión por una empresa conjunta. Sus relaciones se definen en tres dimensiones: compromiso mutuo, una empresa conjunta y un repertorio compartido, que significa «rutinas, palabras, herramientas, formas de hacer las cosas, historias, gestos, símbolos, géneros, acciones o conceptos que la comunidad ha producido o adoptado en el curso de su existencia y que se han con-

26. Esto coincide con muchas de las interpretaciones actuales del concepto hegeliano del derecho (véase Honneth, 2013). 
vertido en parte de su práctica» (Wenger, 1998: 83). Luego, el académico de relaciones internacionales Emanuel Adler, muy influenciado por Pierre Bourdieu, sugirió que

no hay ninguna razón [...] por la que no podamos identificar comunidades de práctica transnacionales o incluso globales. Cuanto más nos acercamos al nivel de prácticas, de hecho, más podemos tomar el sistema internacional como una colección de comunidades de práctica; por ejemplo, comunidades de diplomáticos, comerciantes, ambientalistas y activistas de derechos humanos. Las comunidades de práctica atraviesan las fronteras estatales y median entre los Estados, los individuos y la agencia humana, por un lado, y las estructuras y sistemas sociales, por el otro (Adler, 2005: 15).

Las comunidades de prácticas han sido consideradas por los expertos en derecho internacional. Toope y Brunnée (2010) han aplicado la noción, completándola con una reinterpretación de los criterios fullerianos de la moralidad interna del derecho, para analizar el problema de la obligación jurídica internacional. Para los autores, las comunidades de expertos transnacionales brindan el espacio de interacción que crea el surgimiento de tales obligaciones: «La obligación jurídica, entonces, se ve mejor como un compromiso internalizado y no como un deber impuesto externamente que se corresponde con una sanción por incumplimiento» (Toope y Brunnée, 2010: 115).

Nuestro interés en este punto no es explorar el origen de la obligación jurídica subyacente al derecho común de los derechos humanos en América Latina. Más bien, usamos la noción de comunidades de práctica para explicar el funcionamiento del constitucionalismo transformador en el continente. Al analizar el funcionamiento del derecho en la región, la noción de comunidades de práctica nos permite lograr un equilibrio entre la agencia y la estructura. En lugar de pensar en la práctica interamericana como una sucesión de eventos que ocurren en la intersección de entidades abstractas (como, por ejemplo, los Estados y las instituciones internacionales), nuestra propuesta es observar las personas que toman las decisiones, sus intereses y temores.

Sin duda, este enfoque conlleva el riesgo, por un lado, de sobrevalorar la agencia de profesionales jurídicos individuales en la configuración del campo jurídico; y, por otro, de minimizar el impacto de factores estructurales, como el género, el origen étnico, el origen geográfico o los medios financieros. Es claro que los factores estructurales, y en particular las estructuras socioeconómicas, influyen en la agencia de los actores. ${ }^{27}$ Pero tales estructuras no son el final de la historia. Esa premisa debe evitarse, en el sentido de que los resultados no están determinados por la estructura, una idea de contingencia absoluta, que presentaría el derecho común de los derechos

27. En el contexto del derecho internacional general, esta tensión ha sido descrita por Urueña (2017: 395-396). 
humanos como resultado de «pura casualidad y voluntad» (Marks, 2009: 10). La noción de comunidad de práctica, que se coloca entre las limitaciones de la estructura y la agencia de los individuos, trata de lograr ese equilibrio.

Una comunidad de práctica no implica homogeneidad. Los actores a menudo tienen distintos proyectos, así como diferentes puntos de vista sobre los derechos humanos. La comunidad de práctica está constituida no por un único objetivo, sino por un entendimiento común compartido de lo que están haciendo y por qué (Adler, 2005: 22). ${ }^{28} \mathrm{Al}$ mismo tiempo, la comunidad latinoamericana de derechos humanos comparte un marco: sus instituciones, sus actores y los desafíos a enfrentar, es decir, un sentido de propósito y sus realidades. En este marco existen muchos puntos de vista sobre los derechos humanos interamericanos, pero la interacción continua establece el significado de una norma internacional para un caso dado.

A través del prisma de la práctica social, la idea de una división aguda entre lo nacional y lo internacional, por un lado, y la mentalidad jerárquica de un supuesto diseño constitucionalista en el que la Corte Interamericana estaría en un nivel superior, por el otro, carece de sentido. La Corte IDH está en el centro de una comunidad de práctica que incluye actores nacionales e internacionales: jueces nacionales, funcionarios públicos nacionales, comisionados interamericanos, secretarios, litigantes, académicos; en otras palabras, todos aquellos que contribuyen a las interacciones que crean decisiones jurídicas. Esta comunidad no debe entenderse como un «sistema» que pretende ser coherente. De hecho, la práctica puede desencadenar respuestas conflictivas a preguntas jurídicas específicas. El punto es un propósito compartido de transformación social a través del derecho. Por lo tanto, el derecho común de los derechos humanos no es un castillo en el cielo, sino más bien el proyecto profesional de miles de personas y, a veces, un salvavidas para las víctimas.

El tiempo, las interacciones reiteradas y el aprendizaje son cruciales para esta práctica. Es difícil entender cómo funciona el sistema cuando se conceptualiza la interacción entre actores como una cuestión de encuentros aislados. Aunque este podría ser el caso de algunos funcionarios nacionales, que se enfrentan a la Corte una o dos veces en su mandato, ciertamente no es el caso de los jueces nacionales, las instituciones nacionales de derechos humanos o las organizaciones de víctimas, todos usuarios frecuentes del sistema. La teoría de juegos demuestra con claridad la diferencia entre juegos individuales (aislados) y los juegos iterativos. ${ }^{29} \mathrm{La}$ iteración crea una interacción que es cualitativamente diferente de la del contacto aislado, ya

28. La noción de comunidades de práctica ha sido criticada por guardar silencio sobre el tema de los desequilibrios de poder; por ejemplo, en Contu y Willmott (2003). Sin embargo, nuestra lectura de la práctica de los derechos humanos de la comunidad latinoamericana toma en cuenta las diferencias de poder, ya que considera a muchos actores y no solo a los Estados y organizaciones intergubernamentales.

29. Véase Samuelson y Mailath, (2006). Para el derecho internacional, véase Setear $(1996,1997)$. 
que este proceso constante de interacción y aprendizaje da forma a las expectativas del sistema interamericano. La iteración cambia no solo las estrategias dentro de un juego, sino también el juego en sí (Frischmann, 2003). Las relaciones internacionales constructivistas también han explorado esta idea: la interacción entre los agentes desarrolla la estructura, pero ser parte de la estructura impacta en los intereses y estrategias de los agentes (Adler, 2005: 5-6; Wendt, 1987).

La dimensión social demuestra otra característica del derecho común latinoamericano: la percepción de muchos actores de la comunidad de que el derecho común les permite cumplir mejor sus propios mandatos. Tanto la Convención Americana como la mayoría de las constituciones nacionales confían a todas las autoridades públicas, no solo a los jueces, la tarea de abordar los desafíos de la violencia, la exclusión social y la debilidad de las institucional, en el marco de sus poderes y procedimientos. En ese contexto, la interacción con la Corte Interamericana se ha convertido en una dimensión importante del mandato de las instituciones nacionales de derechos humanos en la región. Así, es común que tales instituciones adopten la interpretación evolutiva de la Convención de la Corte Interamericana y promuevan los derechos humanos en sus respectivos Estados con base en tal entendimiento (Pegram, 2012). El Tribunal, a su vez, interpreta de manera expansiva los poderes atribuidos en el artículo 69.2 de sus reglas de procedimiento. Así, la Corte depende directamente de las instituciones nacionales de derechos humanos para cooperar en el proceso de cumplimiento de sus órdenes -incluso en contra de los deseos del Gobierno respectivo- o para intervenir en los procedimientos judiciales como actores independientes. La Corte, por lo tanto, acerca a esas instituciones a la comunidad de práctica. Como ejemplo podemos tomar el caso en Artavia Murillo con Costa Rica, en el cual la Defensoría del Pueblo de Costa Rica intervino en la audiencia pública sobre el monitoreo del cumplimiento; o el caso Vélez Loor con Panamá, en que la Defensoría panameña intervino en una audiencia privada de cumplimiento. ${ }^{30}$

Por supuesto, incontables dificultades siguen sin resolverse en el derecho común de derechos humanos. Sin embargo, algunas críticas parecen poco persuasivas. No es el caso que la Corte Interamericana defienda la supremacía incondicional de todas sus decisiones para todos los tribunales nacionales, en todas las situaciones. Por el contrario, el llamado ha sido el de tomar soluciones matizadas (véase, por ejemplo, Ferrer Mac-Gregor, 2016). Contra una mentalidad top-down, puramente «constitucionalista», el derecho común de los derechos humanos apunta a un complejo proceso de constante aprendizaje y adaptación. Si nos fijamos en sus homónimos, es decir,

30. Sentencia del caso Artavia Murillo y otros (Fertilización In Vitro) con Costa Rica, Corte Interamericana de Derechos Humanos, fondo, 28 de noviembre de 2012; y sentencia del caso Vélez Loor con Panamá, objeciones preliminares, fondo, reparaciones y costas, serie C núm. 132, 23 de noviembre de 2010, párr. 94. 
el common law en inglés y el ius commune continental europeo, ambos han sido herramientas flexibles, muy sensibles a los contextos políticos y sociales y, por lo tanto, buenos ejemplos en este respecto.

El concepto de una comunidad de práctica destaca otra característica importante: la creencia compartida de que existe un derecho latinoamericano común, que abarca la Convención Americana, su jurisprudencia y elementos de los sistemas jurídicos nacionales. Esta dimensión tiene un lado performativo crucial. El derecho común no se encuentra «allá afuera», en alguna fuente misteriosa. Por el contrario, el derecho común es un proceso que implica definir ciertos fenómenos usando el término ius constitutionale commune en América Latina. Tal denominación puede dar vida a una cierta realidad a través del poder de la palabra. Sin embargo, la etiqueta de derecho común es solo una expresión de la realidad social que es fácilmente observable en la región. Este derecho común de derechos humanos no es solo otra etiqueta académica, sino que existe en los corazones y las mentes, en palabras y esperanzas, de muchos latinoamericanos.

En consecuencia, es posible afirmar la existencia de una nueva comunidad de práctica que crea un nuevo fenómeno jurídico, compuesta de elementos originados en diferentes órdenes jurídicos y conectada por un impulso común. Una nueva ola de constitucionalismo que creó entornos jurídicos para un proyecto constitucional transformador en toda la región. Una comunidad de práctica que dio vida a estándares jurídicos que, según la Corte Interamericana de Derechos Humanos, juegan un papel central en dicho proyecto. El resultado es un derecho común de derechos humanos que fortaleció a la comunidad latinoamericana de derechos humanos en general, lo cual nos ayuda a entender cómo el constitucionalismo transformador internacional sí funciona en América Latina.

\section{Conclusión: Celebrando 40 años de cambios}

En agosto de 2018, la Corte celebró en San José de Costa Rica el aniversario número 40 de la entrada en vigor de la Convención. Tales celebraciones de instituciones internacionales no son una pérdida de tiempo, esfuerzo o fondos (Vauchez, 2012: 51-71). Más bien, sirven a la operación de esas instituciones. Alimentan sus recursos más preciados: su legitimidad social y sus respectivas comunidades de práctica. De hecho, la Corte Interamericana se puso entre bastidores en el evento de San José, desviando la atención a las voces de la comunidad latinoamericana de derechos humanos.

En gran medida, la celebración fue un éxito. Un indicador es el número y el perfil de sus asistentes..$^{31}$ Instituciones claves del Poder Ejecutivo han respaldado a la Corte.

31. "More than 1,500 persons attend the week of events in commemoration of the 4oth anniversary of creation of the Inter-American Court of Human Rights», Corte Interamericana de Derechos Humanos, 
El presidente de Costa Rica, quien ganó el cargo en una plataforma pro Corte Interamericana, intervino dos veces para expresar su profundo compromiso con el sistema, a pesar de una situación de conflicto político interno respecto de la autoridad de la Corte. ${ }^{32} \mathrm{El}$ secretario general de Naciones Unidas, probablemente el más alto representante del sistema internacional, también estuvo presente en esta celebración en honor a la Corte y expresó su apoyo irrestricto al sistema interamericano. Dicho apoyo no se puede dar por sentado, si consideramos la tensión subyacente entre los sistemas regionales y universales: después de todo, la fragmentación del derecho internacional continúa siendo un problema (Payandeh, 2015).

Con respecto al Poder Judicial, la celebración mostró a la Corte Interamericana como parte de una red de tribunales tanto nacionales como internacionales. Los otros dos tribunales regionales de derechos humanos (europeo y africano) participaron en el evento y se concluyó con un acuerdo de cooperación..$^{33}$ Dada la audacia de la Corte Interamericana con la doctrina del control de convencionalidad, la presencia de jueces nacionales, en especial de aquellos tribunales con tensiones, fue particularmente significativa. ${ }^{34}$ Todos expresaron su apoyo al sistema interamericano de derechos humanos en general y a la Corte en particular. Tal apoyo es valioso sobre todo al considerar que también se expresaron profundos desacuerdos. Por supuesto, la dimensión real del apoyo de los poderes judiciales nacionales a la Corte no puede inferirse de estas pocas declaraciones. Pero lo cierto es que la Corte Interamericana no está sola.

La participación de varias organizaciones sociales, así como de víctimas individuales, fue notable. Quedó claro que la comunidad latinoamericana de derechos humanos no está compuesta solo por instituciones oficiales. Las personas y los grupos de personas tienen un papel activo, en particular las víctimas que recibieron ayuda. La amplitud y profundidad del sistema interamericano, el hecho de que vincula diferentes instituciones nacionales y la sociedad civil, nutre la legitimidad de la Corte. El sistema se basa en una sólida red de miles y miles de personas cuyo objetivo es transformar la región como parte de la comunidad latinoamericana de práctica de derechos humanos.

Las celebraciones esbozaron quién pertenece a esa comunidad, o al menos a su parte interamericana. Un sistema jurídico a menudo se identifica por sus casos prin-

23 de julio de 2018, disponible en https://bit.ly/2RQuqX2.

32. Álvaro Murillo, «Costa Rica y la Corte Interamericana cumplen, entre presiones, 40 años de una relación estrecha», Semanario Universidad, 17 de julio de 2018, disponible en https://bit.ly/3kI6TnA.

33. "More than...», 2.

34. Corte Suprema Federal de Brasil, Corte Constitucional de Guatemala, Corte Suprema de Justicia Chile, Corte Suprema de Justicia de la Nación (México), Corte Constitucional de Colombia y Corte Suprema de Costa Rica. "40 aniversario de la entrada en vigor de la Convención Americana sobre Derechos Humanos y de la creación de la Corte Interamericana de Derechos Humanos», Corte Interamericana de Derechos Humanos, programa del 19 de julio de 2018, disponible en https://bit.ly/3mICSWd. 
cipales, aquéllos que son constantemente invocados por sus miembros y que forman parte de su narrativa. En la publicación preparada para su aniversario, «40 Años Protegiendo Derechos», el propio Tribunal destacó las decisiones que considera fundamentales (Corte IDH, 2018: 42-55). Varios participantes reiteraron la importancia de esas decisiones, muchas de las cuales se discutieron en este capítulo. Otro elemento central de la identidad es el propósito del sistema. Sobre este tema, hubo un consenso más amplio durante las celebraciones: combatir la violencia y la exclusión social $\mathrm{y}$ fortalecer las instituciones. La creencia de estar involucrados en un proyecto tan importante fortalece a cualquier comunidad.

Una cosa que faltaba en las celebraciones del cuadragésimo aniversario del sistema interamericano fueron las críticas serias. En cierto modo, el silencio sobre este asunto es comprensible, considerando una percepción generalizada del sistema como débil y amenazado por fuerzas hostiles. Dado que estas celebraciones han demostrado la legitimidad de que goza el sistema, existen buenas razones para buscar la fuerza innovadora que proviene de la crítica (Hirschmann, 1994: 202-212).

En este sentido, nos vienen a la mente varios temas. Se podría discutir si el corpus iuris latinoamericano completo es en realidad un logro. Es poco probable que esto sea así, a la luz de la complejidad de los asuntos que llegan a la Corte. ${ }^{35}$ Se debe hacer una revisión crítica desde dentro de la comunidad latinoamericana. Tratar de identificar las diez peores decisiones y cómo lidiar con ellas podría generar críticas constructivas que terminen fortaleciendo el sistema.

Luego, hay una tensión, o incluso una paradoja, que surgió regularmente durante las celebraciones. Muchos elogiaron la contribución de la Corte a los derechos humanos en la región y, al mismo tiempo, lamentaron cuán terrible es la situación de los derechos humanos. Por un lado, parece haber habido progreso; por otro, parece que no ha habido cambios sustanciales. ¿Cómo se relacionan estas dos afirmaciones? ¿Es suficiente afirmar que la situación sigue siendo terrible porque no se respetan los derechos humanos? ¿O hay quizás causalidades más complejas detrás de todo? (Kennedy, 2004; Moyn, 2018). Explorar este asunto podría conducir a otro ángulo crítico.

También podría valer la pena involucrar a aquéllos que no consideran que el sistema sea tan bueno. Hay quienes creen que la Corte debería ser más formalista y que su manera actual de razonamiento socava la racionalidad específica del derecho. Hay quienes creen que los objetivos del sistema se alcanzan mejor a través de otros mecanismos, que podrían verse frustrados por un énfasis innecesario en el lenguaje jurídico de los derechos humanos. Hay quienes creen que la agenda de derechos humanos se interpone en el camino de un proyecto de verdad importante: avanzar hacia sociedades más justas mediante la obtención de un crecimiento económico robusto.

35. Por ejemplo, la discusión sobre la fortaleza analítica de la jurisprudencia de ius cogens. Véase Contreras-Garduno y Alvarez-Rio (2016) y Neuman (2008). 
Por último, hay quienes creen que este proyecto transnacional está construido sobre arena, precisamente porque es un proyecto transnacional.

El sistema interamericano de derechos humanos, a pesar de toda la profundidad y aliento que ha adquirido en los últimos 40 años, es solo una de las diversas fuerzas que compiten para dar forma al futuro de las Américas. Para continuar su camino exitoso, el constitucionalismo transformador debe construir coaliciones más fuertes. Eso también debe entenderse como parte del mandato del sistema.

\section{Reconocimiento}

Este capítulo se basa en parte en una versión previa del texto publicado, con numerosos cambios, como «International transformative constitutionalism in Latin America», en American Journal of International Law, número 114 (2000), pp. 1-85. La versión presentada aquí fue objeto de cambios y actualización en el texto finalmente publicado.

\section{Referencias}

Acosta Alvarado, Paola Andrea (2015). Diálogo judicial y constitucionalismo multinivel: El caso interamericano. Bogotá: Universidad Externado de Colombia.

AdLER, Emanuel (2005). Communitarian international relations: The epistemic foundations of international relations. Londres y Nueva York: Routledge.

ATRIA, Fernando, Constanza Salgado y Javier Wilenmann (2020). El proceso constituyente en 138 preguntas y respuestas. Santiago: Lom.

Azuero Quijano, Alejandra (2009). «Redes de diálogo judicial trasnacional: Una aproximación empírica al caso de la Corte Constitucional». Revista de Derecho Público, 22: 1-23. Disponible en https://bit.ly/362t43M.

BINDER, Christina (2010). «Hacia una Corte Constitucional latinoamericana? La jurisprudencia de la Corte Interamericana de Derechos humanos con enfoque especial sobre las amnistías». En Armin von Bogdandy, Eduardo Ferrer Mac-Gregor y Mariela Morales Antoniazzi (editores), La justicia constitucional y su internacionalización (pp. 156-188). Ciudad de México: UNAM.

Bonilla, Daniel (editor) (2013). Constitutionalism of the Global South: The activist tribunals of India, South Africa, and Colombia. Cambridge: Cambridge University Press.

Burgorgue-LARSEN, Laurence (2017). «The added value of the Inter-American Human Rights System: Comparative thoughts». En Armin von Bogdandy, Eduardo Ferrer Mac-Gregor, Mariela Morales Antoniazzi y Flávia Piovesan (editores), Transformative constitutionalism in Latin America: The emergence of a new ius commune (pp. 377-408). Oxford: Oxford University Press. 
Caicedo Tapia, Danilo Alberto (2009). «El bloque de constitucionalidad en el Ecuador: Derechos humanos más allá de la Constitución». Foro: Revista de Derecho, 12: 5-29. Disponible en https://bit.ly/3iXlzyC.

Céballos Méndez, Edward Jonathan (2009). «Participación ciudadana en el marco de la Constitución de la República Bolivariana de Venezuela y los Consejos Comunales». Provincia, 21: 43-6o. Disponible en https://bit.ly/3j1cCnS.

Comisión Nacional sobre la Desaparición de Personas (1984). Nunca más: Informe de la Comisión Nacional sobre la Desaparición de Personas. Buenos Aires: Universitaria.

Contreras-Garduno, Diana e Ignacio Alvarez-Rio (2016). «A barren effort? The jurisprudence of the Inter-American Court of Human Rights on jus cogens». Revista do Instituto Brasileiro de Direitos Humanos, 14: 113-132. Disponible en https:// bit.ly/2FYZWzo.

Contu, Alessia y Hugh Willmott (2003). «Re-embedding situatedness: The importance of power relations in learning theory». Organization Science, 14 (3): 283-296. DOI: 10.1287 /orsc.14.3.283.15167.

CoRTe IDH, Corte Interamericana de Derechos Humanos (2018). 40 años protegiendo derechos. San José: Corte IDH y GIZ.

Cuesta López, Víctor, Juan Fernando López Aguilar y Juan Rodríguez-Drincourt (2008). Participación directa e iniciativa legislativa del ciudadano en democracia constitucional. Madrid: Civitas.

Cumplido Cereceda, Francisco (1996). «Alcances de la modificación del artículo 5 de la Constitución Política chilena en relación a los tratados internacionales». Revista Chilena de Derecho, 23 (2-3): 255-258. Disponible en https://bit.ly/3cngUql.

Dezalay, Yves y Bryant G. Garth (2002). The internationalization of palace wars: Lawyers, economists, and the contest to transform Latin American states. Chicago: University of Chicago Press.

Ferrer MaC-Gregor, Eduardo (2015). "Conventionality control the new doctrine of the Inter-American Court of Human Rights». American Journal of International Law, 109: 93-99. DOI: 10.1017/S2398772300001240.

-. (2016). «El control de convencionalidad como un vehículo para el diálogo judicial entre la Corte Interamericana de Derechos Humanos y los tribunales de América». Anuario de Derecho Constitucional Latinoamericano, 2016: 337-356. Disponible en https://bit.ly/3mJc34l.

FrischmanN, Brett (2003). "A dynamic institutional theory of International Law». Buffalo Law Review, 51: 679-809. Disponible en https://bit.ly/33U1ZwU.

Góngora Mera, Manuel (2011). Inter-American judicial constitutionalism: On the constitutional rank of human rights treaties in Latin America through national and Inter-American adjudication. San José: Instituto Interamericano de Derechos Humanos. 
Häberle, Peter y Markus Kotzur (2003). De la soberanía al derecho constitucional común. Ciudad de México: UNAM.

Hailbronner, Michaela (2017). «Transformative constitutionalism: Not only in the Global South». The American Journal of Comparative Law, 65 (3): 527-565. DOI: 10.1093/ajcl/avxo16.

Henríquez, Miriam y Mariela Morales Antoniazzi (editoras) (2017). El control de convencionalidad: Un balance comparado a 10 años de Almonacid Arellano vs. Chile. Santiago: DER.

HirschmanN, Albert O. (1994). «Social conflicts as pillars of democratic market society». Political Theory, 22 (2): 203-218. DOI: 0.1177/0090591794022002001.

Honneth, Alex (2013). Das Recht der Freiheit: Grundriß einer demokratischen Sittlichkeit. Berlín: Suhrkamp.

Huerta Malbrán, María Antonieta (2000). Descentralización, municipio y participación ciudadana: Chile, Colombia y Guatemala. Bogotá: CEJA.

KENNEDY, David (2004). The dark sides of virtue: Reassessing international humanitarianism. Princeton: Princeton University Press.

KLARE,KarlE. (1998). «Legal cultureand transformative constitutionalism». South African Journal on Human Rights, 14 (1): 146-188. DOI: 10.1080/02587203.1998.11834974.

LAVE, Jean y Etienne Wenger (1991). Situated learning: Legitimate peripheral participation. Cambridge: Cambridge University Press.

MARKs, Susan (2009). «False contingency». Current Legal Problems, 62 (1): 1-21. DOI: 10.1093/clp/62.1.1.

Márquez Restrepo, Martha Lucía, Eduardo Pastrana Buelvas y Guillermo Hoyos Vásquez (2009). Democracia y ciudadanía: Problemas, promesas y experiencias en la región andina. Bogotá: Pontificia Universidad Javeriana.

Morales Antoniazzi, Mariela (2014). Protección supranacional de la democracia en Suramérica: Un estudio sobre el acervo del ius constitutionale commune. Ciudad de México: UNAM.

Morales Antoniazzi, Mariela y Pablo Saavedra Alessandri (2017). «Inter-Americanization: Its legal bases and political impact». En Armin von Bogdandy, Eduardo Ferrer Mac-Gregor, Mariela Morales Antoniazzi y Flávia Piovesan (editores), Transformative constitutionalism in Latin America: The emergence of a new ius commune (pp. 255-278). Oxford: Oxford University Press.

Moyn, Samuel (2018). Not enough: Human rights in an unequal world. Cambridge: Harvard University Press.

Nash Rojas, Claudio (2013). "Control de convencionalidad: Precisiones conceptuales y desafíos a la luz de la jurisprudencia de la Corte Interamericana de Derechos Humanos». Anuario de Derecho Constitucional Latinoamericano, 2013: 489-509. Disponible en https://bit.ly/3kUFkrh. 
Neuman, Gerald L. (2008). «Import, export, and regional consent in the Inter-American Court of Human Rights». European Journal of International Law, 19 (1): 101123. DOI: 10.1093/ejil/chnoo2.

Novoa Monreal, Eduardo (1975). El derecho como obstáculo al cambio social. Ciudad de México: Siglo Veintiuno.

Payandeh, Mehrdad (2015). «Fragmentation within International Human Rights Law». En Mads Andenas y Eirik Bjorge (editores), A farewell to fragmentation: Reassertion and convergence of International Law (pp. 297-319). Cambridge: Cambridge University Press.

Pegram, Thomas Innes (2012). «National human rights institutions in Latin America: Politics and institutionalization». En Ryan Goodman y Thomas Innes Pegram (editores), Human rights, state compliance, and social change: Assessing national human rights institutions (pp. 210-240). Cambridge: Cambridge University Press.

ReED-Danahay, Deborah (2005). Locating Bourdieu. Bloomington: Indiana University Press.

Restrepo Piedrahita, Carlos (1978). Tres ideas constitucionales: Supremacía de la constitución, Corte Constitucional, el ombudsman. Bogotá: Universidad Externado de Colombia.

Rodríguez Garavito, César A. (2009). La globalización del Estado de derecho: El neoconstitucionalismo, el neoliberalismo y la transformación institucional en América Latina. Bogotá: Universidad de Los Andes.

-. (2015). Radical deprivation on trial: The impact of judicial activism on socioeconomic rights in the Global South. Cambridge: Cambridge University Press.

Roux, Theunis (2009). «Transformative constitutionalism and the best interpretation of the South African Constitution: Distinction without a difference». Stellenbosch Law Review, 20 (2): 258-285.

SAGÜÉs, Néstor Pedro (2010). «Obligaciones internacionales y control de convencionalidad». Estudios Constitucionales, 8 (1): 117-136. DOI: 10.4067/ So718-52002010000100005.

Salamanca, Luis (2000). «La Constitución venezolana de 1999: De la representación a la hiper-participación ciudadana». Revista de Derecho Público, 82: 85-105. Disponible en https://bit.ly/3coUCBn.

SAmuelson, Larry y George Joseph Mailath (2006). Repeated games and reputations: Long-run relationships. Oxford: Oxford University Press.

SETEAR, John (1996). "An iterative perspective on treaties: A synthesis of international relations theory and International Law». Harvard International Law Journal, 37 (1): 139-230.

-. (1997). «Responses to breach of a treaty and rationalist international relations theory: The rules of release and remediation in the Law of Treaties and the Law of State Responsibility». Virginia Law Review, 83 (1): 1-126. DOI: 10.2307/1073740. 
SikкINK, Kathryn y Margaret Keck (1998). Activists beyond borders. Ithaca: Cornell University Press.

SRIPATI, Vijayashri (2007). «Constitutionalism in India and South Africa: A comparative study from a human rights perspective». Tulane Journal of International Comparative Law, 16: 49-116. Disponible en https://bit.ly/32SMshw.

STEIN, Eric (1981). «Lawyers, judges, and the making of a transnational constitution». The American Journal of International Law, 75 (1): 1-27. DOI: 10.2307/2201413.

Toope, Stephen J. y Jutta Brunnée (2010). Legitimacy and legality in international law: An interactional account. Cambridge: Cambridge University Press.

UPRIMNY, Rodrigo (2010). «The recent transformation of Constitutional Law in Latin America: Trends and challenges». Texas Law Review, 89 (7): 1.587-1.609.

URUEÑA, René (2017). «International Law as expert knowledge: Exploring the changing role of international lawyers in national contexts». En Jean d'Aspremont, Tarcisio Gazzini, André Nollkaemper y W. G. Werner (editores), International law as a profession (pp. 389-410). Cambridge: Cambridge University Press.

-. (2019). «Domestic application of International Law in Latin America». En Curtis A. Bradley (editor), The Oxford handbook of comparative foreign relations law (pp. 565-582). Oxford: Oxford University Press.

VAUCHEZ, Antoine (2012). «Keeping the dream alive: The European Court of Justice and the transnational fabric of integrationist jurisprudence». European Political Science Review, 4: 51-71. DOI: 10.1017/S1755773911000105.

Venter, Francois (2018). "The limits of transformation in South Africa's constitutional democracy». South African Journal of Human Rights, 34 (2): 143-166. DOI: 10.1080/02587203.2018.1509495.

Villarroel Alarcón, José Ismael (2017). «El tratamiento del derecho internacional en el sistema jurídico boliviano». En Paola Acosta Alvarado, Juana Inés Acosta López y Daniel Rivas Ramírez (editores), De anacronismos y vaticinios: Diagnóstico sobre las relaciones entre el derecho internacional y el derecho interno en Latinoamérica (pp. 29-66). Bogotá: Universidad de La Sabana, Universidad Externado de Colombia.

Von Bogdandy, Armin (2020). «El mandato del Sistema Interamericano: Constitucionalismo transformador por un derecho común de derechos humanos». En Corte Interamericana de Derechos Humanos (compilador), Diálogo entre cortes regionales de derechos humanos (pp. 63-74). San José: Corte Interamericana de Derechos Humanos.

Von Bogdandy, Armin, Eduardo Ferrer Mac-Gregor, Mariela Morales Antoniazzi y Flávia Piovesan (editores) (2017). Transformative constitutionalism in Latin America: The emergence of a new ius commune. Oxford: Oxford University Press. 
Von Bogdandy, Armin, Héctor Fix-Fierro y Mariela Morales Antoniazzi (editores) (2014). Ius constitutionale commune en América Latina: Rasgos, potencialidades y desafíos (pp. 156-199). Ciudad de México: UNAM.

Von Bogdandy, Armin y Mariela Morales Antoniazzi (2020). «Aproximación a la política de derechos humanos en América Latina: Una mirada desde el ius commune». En Armin von Bogdandy, Transformaciones del derecho público: Fenómenos internacionales, supranacionales y nacionales. Querétaro: MPIL, IIJ-UNAM, Instituto de Estudios Constitucionales de Querétaro.

Wenger, Etienne (1998). Communities of practice: Learning, meaning, and identity. Cambridge: Cambridge University Press.

WeNDT, Alexander (1987). «The agent-structure problem in international relations». International Organization, 41 (3): 335-370. DOI: $10.1017 /$ So02081830002751X.

Welp, Yanina (2008). «La participación ciudadana en la encrucijada: Los mecanismos de democracia directa en Ecuador, Perú y Argentina». Íconos: Revista de Ciencias Sociales, 31: 117-130. DOI: 10.17141/iconos.31.2008.267.

\section{Sobre los autores}

Armin von Bogdandy es director del Instituto Max Planck de Derecho Público Comparado y Derecho Internacional en Heidelberg y profesor de Derecho Público en la Universidad de Frankfurt am Main, Alemania. Se licenció en Derecho y Filosofía antes de obtener un doctorado en Friburgo (1988) y como profesor en la FU Berlín (1996). Ha sido presidente del Tribunal de Energía Nuclear de la OCDE, miembro del Consejo Científico Alemán (Wissenschaftsrat) y del Comité Científico de la Agencia de Derechos Fundamentales de la Unión Europea. Ha ocupado cargos de invitado en la Escuela de Derecho de la Universidad de Nueva York, el Instituto Universitario Europeo, la Academia de Derecho Internacional de Xiamen y la Universidad Nacional Autonóma de México, entre otros. Su correo electrónico es sekreavb@mpil.de.

RenÉ URUeÑa es abogado con especialización en Economía de la Universidad de los Andes, Colombia, y doctor en Derecho de la Universidad de Helsinki, Finlandia. Director del área de Derecho Internacional de la Universidad de Los Andes. Su correo electrónico es rf.uruena21@uniandes.edu.co. 
El Anuario de Derechos Humanos es una publicación semestral de referencia y consulta en materia de derechos humanos y campos afines. Busca ser un espacio de discusión de los temas centrales en el ámbito nacional e internacional sobre derechos humanos. Es publicado desde 2005 por el Centro de Derechos Humanos de la Facultad de Derecho de la Universidad de Chile.

\author{
EDITORA GENERAL \\ Claudia Iriarte Rivas \\ ciriarter@derecho.uchile.cl \\ EDITORA DE ESTE NÚMERO \\ Liliana Galdámez Zelada \\ lgaldamez@derecho.uchile.cl \\ SITIO WEB \\ anuariocdh.uchile.cl \\ CORREO ELECTRÓNICO \\ anuario-cdh@derecho.uchile.cl \\ LICENCIA DE ESTE ARTÍCULO
}

Creative Commons Atribución Compartir Igual 4.o Internacional

\author{
कै \\ La edición de textos, el diseño editorial \\ y la conversión a formatos electrónicos de este artículo \\ estuvieron a cargo de Tipográfica \\ (www.tipografica.io)
}

